\title{
IDENTIFYING POTENTIAL AREAS FOR FUTURE URBAN DEVELOPMENT USING GIS-BASED MULTI CRITERIA EVALUATION TECHNIQUE
}

\author{
Khalid Sabbar Mohammed ${ }^{1}$, Yasin Abdalla Eltayeb Elhadary ${ }^{2}$ \& Narimah Samat ${ }^{3}$ \\ ${ }^{1}$ Geography Section- School of Education for Humanities studies \\ University of Al-Anbar -Iraq \\ ${ }^{2}$ Faculty of Geographical and Environmental Science, University of Khartoum, Sudan \\ ${ }^{3}$ Geography Section, School of Humanities, Universiti Sains Malaysia \\ E-mail: yasingeographya@yahoo.com
}

\begin{abstract}
Malaysia likes other Asian countries has experienced rapid urbanization due to economic development, industrialization, massive migrations as well as natural population growth. This expansion particularly the unplanned has impacted negatively on farming activities and creates huge pressure arable agriculture areas. Thus, identification of potential sites for future urban development should become important issues in ensuring sustainable development. Therefore, the aim of this paper is to use GIS based multi criteria evaluation technique to identify potential areas for urban development at Balik Pulau, Penang. The study quantified spatial and temporal dynamics of land use/cover changes and identified potential areas for future development. The results indicated that large proportions of agriculture areas had been converted to built-up areas.. Urban areas increased from 1793.2 ha in 1992 to 3235.4 ha in 2002 and became 3987.8 ha in 2010. On the other hand agricultural land decreased from 6171.3ha (53.8\%) in 1992 to 3883 ha (35. \%) in 2010. The study, then, produced map showing potential sites for future urban development. The findings also indicated built-up areas would continue to encroach into flat available agricultural land which will be diminished if no restriction imposed. Thus, the information obtained from this study is useful for planners and decision makers in controlling agriculture areas and guiding new development properly.
\end{abstract}

Keywords: GIS-MCE, Remote Sensing, land use land cover changes, Penang Island. 


\section{INTRODUCTION}

Currently, both developed and developing countries have experienced unprecedented expansion of urbanization due to economic development, industrialization, massive migrations as well as natural population growth (Sabbar, et al. 2015). This expansion comes usually at the expense of agricultural land and led in some countries to the condition of food insecurity. According to Elhadary et al., (2013) urbanization and its impact on agriculture worldwide have received considerable attention by planners, researchers, and policymakers. Urbanization has caused significant losses of agricultural and natural lands, areas that are relevant to maintaining both social systems and cultural diversity along with natural systems and biodiversity (Hepinstall et al., 2008). The unplanned and uncontrolled rapid growth has resulted in serious negative effects on the suburban dwellers and their environment (Chadchan and Shankar, 2012). Therefore much attention has been paid to address the issue of urbanization and its negative implication on socio-economic and environment. Sustainable development should be practiced by both developed and developing countries (Raddad et al., 2010) such that urban development would give large consideration to coservation issues such as landscape fragmentation and environmental degredation (Fekade, 2000). Malaysia like other Asian countries has experienced rapid expansion of urban areas (Sabbar, et al. 2015) due among other factors to the shift of economy from a mainly agriculture to an industry based economy in early seventies (Samat, 2010). Urbanization is not a problem of its own but, when drastic increase of urban population occurs especially in the countries that lack resources and personnel to deal with it. In Malaysia, for example, urban population has reached $>72 \%$ and is expected to become $75 \%$ by 2020 (Elhadary and Samat, 2015). In this situation securing sustainable residential areas for urban dwellers is considered as a hard task for urban planners. The residential developments required to focus on the affordability of the residents to live and work with accessibility, infrastructural facilities, environmental quality, financial ability etc. This idea supported by Chen (2014) who stated that land use suitability assessment is a key factor in any urban and suburban planning and decision-making processes. Thus, in dealing with planning decision making, modern techniques are powerful to guide the planners and policy makers for identifying sustainable and affordable urban areas for future development.

Urban land use is a dynamic phenomenon, changing both across space and time (Elhadary and Samat, 2015). Thus, a proper planning shall be undertaken to ensure that new development does not bring negative impact on the society, space and the environment 
(Koomen \& Stillwell, 2007). Available literature have shown that several methods and techniques have been adopted to ensure sustainable urban development. These techniques include Remote Sensing (RS), Geographical Information System (GIS), City works (CW), City Engine (CE), Transit-oriented development (TOD), Cellular Automata (CA) and Multi Criteria Evaluation (MCE). These advanced technologies mainly (GIS) are recognized worldwide as valuable technologies in environmental applications and are very useful in monitoring the environmental changes due to human activity ( $\mathrm{Ma}$ and $\mathrm{Xu}, 2010$; $\mathrm{Xu}$ et al., 2000. GIS procedures involve managing, editing, and analyzing huge volumes of spatial data and their related thematic attributes (Jat et al., 2008). However, available GIS software has limitation in spatial analysis and cartographic modeling, because this software just offers deterministic analysis and overlay of maps (Openshaw, 1996; Fischer and Nijkamp, 1993). To overcome these deficiencies, GIS packages such as IDRISI and SPANS currently include Multi Criteria Evaluation (MCE) modules which are easy and simple to use. MCE simply is a set of procedures designed to facilitate decision making in selecting the proper action from various options offered by the system. According to Weerakoon (2014) the primary concerned of Multi Criteria Evaluation is how to combine the information from several criteria for decision making purposes. In the same line Voogd (1983) states that the basic purpose of MCE is "to investigate a number of choice possibilities in the light of multiple criteria and conflicting objectives". MCE procedures allow assessing a region on the basis of multiple objectives and criteria and support the decision-making in urban and regional planning (Carver, 1996; Chuvieco, 1993). This due to the fact that MCE uses weights of the criteria and is often used in urban planning processes or in solving the complex land problems which require a decision based on the elements of geographical location (Chen et al., 2001). Thus, integration of GIS and MCE could provide a powerful tool for studying allocation of activities and providing the user with the means to evaluate various alternatives on the basis of multiple and conflicting criteria and objectives (Carver, 1996). The combination of GIS and MCE process transforms geographical data (input) into a result decision (output) (Carver, 1991; Heywood et.al., 1995; Malczewski, 1996). In the light of this, this article uses GIS based Multi Criteria Evaluation (MCE) to identify suitable area for urban's residents in Balik Pulau of Penang Island, Malaysia. 


\section{BACKGROUND OF THE STUDY}

Several articles have been published in addressing urban land suitability using Multi Criteria Evaluation (MCE) integrated in Geographical information System environment. Currently, Chen (2014) uses such technique in generating land use suitability of city Regina in Canada. Also Santosh Kumar and Ritesh Kumar (2014) illustrates the use of GIS tools and numerical MCE techniques to identify suitable sites for urban development of a hill town, Nahan in India. In that study, six criteria namely evaluation of slope, road proximity, land use, land values, soil and geomorphology factors were used. Similarly, Liu et al (2007) used comprehensive method of GIS and MCE to analyze the suitability of future land use according to specified requirements, preferences and predictions in Hanyang lake area located in Wuhan city. Dai et al. (2001) conducted a study of the urban land use planning based on GIS and multi-criteria analysis method, which was applied in Lanzhou city, and its vicinity in north-western China. In Malaysia Zubaidah (2010) also used GIS and multi criteria evaluation for identification of suitable urban school sites in Malaysia. In her study decision makers' evaluation and community opinions have been used for developing a set of school siting criteria and school planning data model which were used to design a number of potential sites by using the spatial analysis model.

The above mentioned literature indicated that Multi-Criteria Evaluation (MCE) technique has been widely used in addressing land use suitability in both developed and developing countries. Deficiency of GIS experts, difficulties in accessing spatial soft and hardware and lack of knowledge and awareness among urban planners are some constraints that led to less implementation of this valuable technique were implemented in developing compared to developed countries. Despite the fact that developing countries are impacted negatively by and have to work hard to minimize the negative effects of urbanization and ensure sustainable development. This idea supported by Umrikar (2013) who stated that land suitability analysis for urban expansion is necessary to overcome the problem of constraints in land availability against rapid growth of urbanization. Although various studies have been conducted that utilized GIS and Multi-MCE in investigating potential sites for urban development, its implementation in Penang state,Malaysia was rare (Samat, 2002). Thus, this article focuses predominately on the integration of GIS and MCE for identifying the suitable site for future urban growth in Penang state, Malaysia. Based on data availability five factors that influenced urban development were used in this study: proximity to water bodies, proximity 
to populated areas, proximity to developed areas, existing from land value, and proximity to road networks. The article used Remote sensing RS and GIS based multi criteria evaluation technique to understand the nature of the current urbanization and identify potential areas for near future urban development in Balik Pulau town-Penang State. The paper tries to answer the following questions. What are the major criteria used for identifying the suitable location for residential development in Balik Pulau sub urban area? Which areas are most likely to be developed in the near future in Balik Pulau town?

\section{THE STUDY AREA}

Balik Pulau literarily means back of the island, is located at the southwest district of Penang State and was chosen as the study area. It is one of the thirteen parliamentary constituencies in Penang state, the largest in land size, stretching about half of Penang Island. Geographically, Balik Pulau is located between $5^{\circ} 24^{\prime} 27^{\prime \prime}$ and $5^{\circ} 18^{\prime} 46^{\prime \prime} \mathrm{N}$ and $100^{\circ} 11^{\prime} 35^{\prime \prime}$ and $100^{\circ} 14^{\prime} 21^{\prime \prime}$ E. It covers an area of $86 \mathrm{~km}^{2}$, accounting for $28 \%$ of the total land area in Penang Island (see Figure 1). The number of population was approximately 29,218 in the 2000 and it has increased to 34,219 in 2010 (Department of Statistics, Malaysia, 2001; 2010). The study area included 14 sub-districts (mukims) that vary in terms of area covered and number of population density (Abdul Rahman, 2000). Topographically, the study area is almost flat with some interior hills which its highest ranges between $300 \mathrm{~m}$ and $800 \mathrm{~m}$ (Rainis, et al. 2002). Most of the flat area is occupied by built up areas and some agricultural activities such as rice fields and fruit orchards as well as coastal areas. This area has experienced urban development pressure since 1970, when Malaysia had embarked on industrialization policy as catalyst of economic growth (Samat, 2002; Chan, 2010). The heavy demand for industrial areas and housing has led to massive reduction in agricultural lands particularly at the periphery of the urban centers. This offers the study an opportunity to measure the loss of productive land and thus facilitate decision makers in formulating rational policies to protect agricultural land. Another reason for selecting the Balik Pulau is due to data availability. Data availability is an important issue in monitoring land use changes since data input and database creation is time consuming and costly (Samat, 2006). 


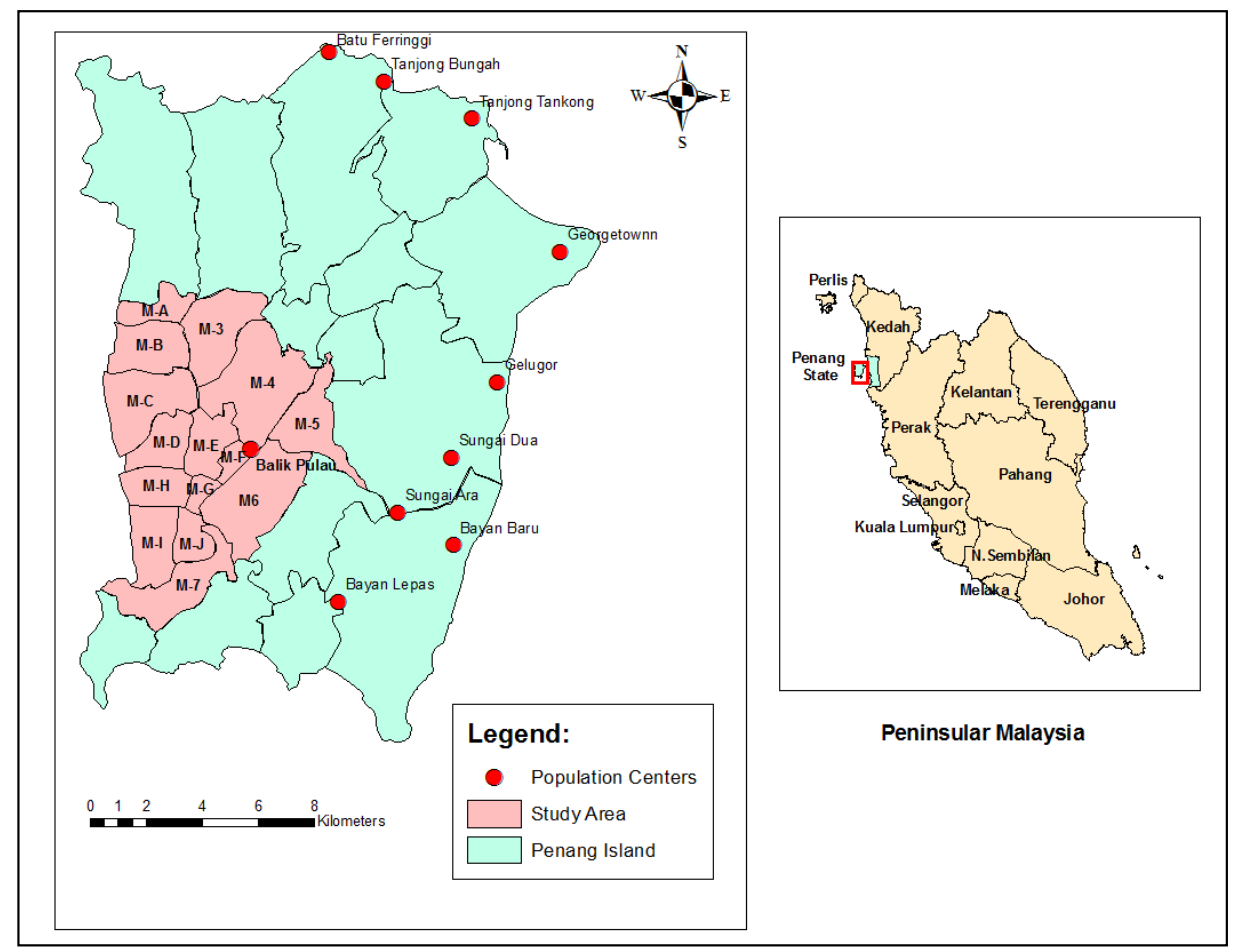

Figure1. Location of study area: Southwest of Penang Island

\section{MATERIALS AND GENERAL PROCEDURES OF DATA PROCESSING}

The study utilized three main land use maps (1967, 1974, and 2010) with the scale of 1:150,000. The data were gathered from different sources; the maps of 1967 and 1974 were collected from Universiti Sains Malaysia (USM), and the map of 2010 was obtained from Town and Country Planning Department, Penang State. Roads network and elevation data at the scale of 1:150,000 were gathered from USM. Other data such as Penang cadastral lot, Penang district and Penang Sub-districts were also obtained from USM in Arcview shapefile format In addition, image Landsat data (TM 1992, ETM 2002) were acquired from USGS remote sensing website and THEOS 2010 acquired from School of Physics, USM. These images were used to examine the rate of urban expansion process in Penang Island. Multitemporal remote sensing image of 1992, 2002 and 2010 were used to monitor and detect land use/land cover changes and identify urban expansion in study area.. Table 1 shows the sources of satellite images obtained for this study. The study used ArcGIS 9.3 software to create geo-spatial database and perform the analysis. 
Table 1: Data obtained from satellite imaages

\begin{tabular}{|l|c|c|c|}
\hline Data Availability & year & Source & Existing Format \\
\hline Landsat 7 Satellite image at 30 m resolution & $01-04-2002$ & USGS & 7 bands soft copy \\
\hline Landsat 5 Satellite image at 30 m resolution & $24-06-1992$ & USGS & 7 bands soft copy \\
\hline $\begin{array}{l}\text { THEOS1Scene level 2A Satellite image at 15 m } \\
\text { resolution }\end{array}$ & $29-01-2010$ & USGS & 4 bands soft copy \\
\hline
\end{tabular}

\section{Data Analysis}

Two major analysis namely the change detection analysis and suitability analysis were performed (Figure 2). Change detection analysis was used to calculate the statistics and rate of changes of land use/land cover change from 1992 to 2010 based on Equation 1 and 2 below. (Ma and $\mathrm{Xu} 2009$ )

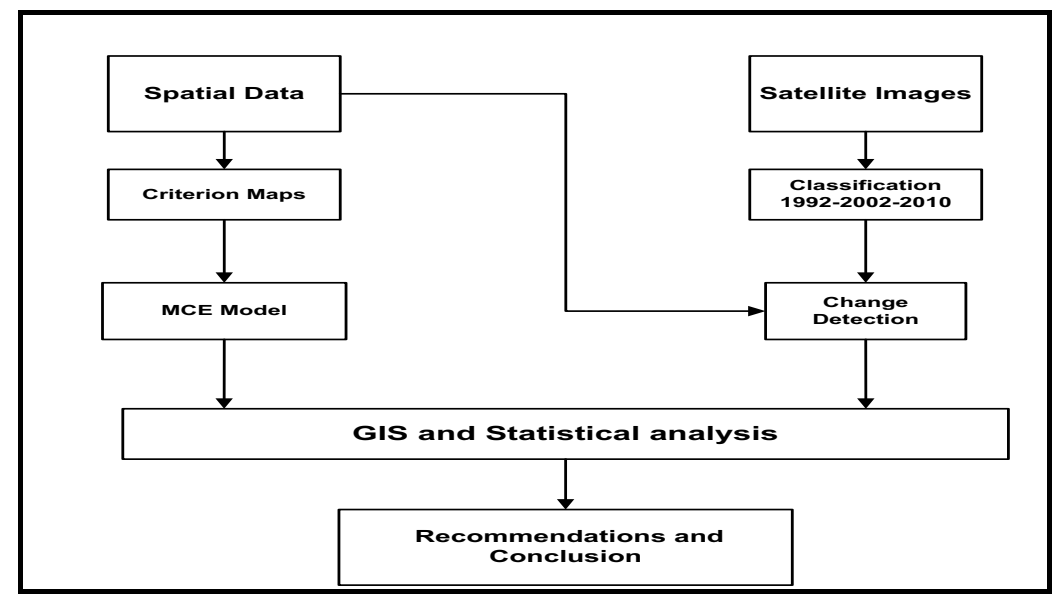

Figure 2: Methodology used in this study.

$$
\Delta L U_{i, j, r}^{t \rightarrow t+1}=L U_{i, j, r}^{t+1}-L U_{i, j, r}^{t}
$$

Where,

$$
\begin{aligned}
& \Delta L U_{i, j, r}^{t \rightarrow t+1}=\text { changes of land use type } r \text { at location } i \text { and } j \text { from } t \text { to } t+1, \\
& L U_{i, j, r}^{t+1}=\text { land use type } r \text { at location } i \text { and } j \text { at time } t+1 \text {, and }
\end{aligned}
$$


$L_{i, j, r}^{t}=$ land use type $r$ at location $i$ and $j$ at time $t$.

$L U D I=\frac{U a-U b}{U a} \times \frac{1}{T} \times 100 \%$

Where,

LUDI $=$ the annual rate of change in area for land use classes.

$\mathrm{Ua}=$ certain land use class at time a

$\mathrm{Ub}=$ certain land use class at time $\mathrm{b}$ and.

$\mathrm{T}=$ denotes the length of time from time a and time $\mathrm{b}$, when $\mathrm{T}$ is in a unit of year,

The second analysis is intended to identify suitable areas for urban development which are likely to experience urban development pressure. GIS and MCE were used to perform this analysis. Data was prepared in ArcGIS 9.3 and transferred to IDRISI Kilimanjaro to perform the analysis. This software is used since it is simple and has integrated MCE module within GIS system, which is useful and easy to be operated especially for non-technical users (Samat, 2002). The procedure used in performing MCE analysis is shown in Figure 3 below.

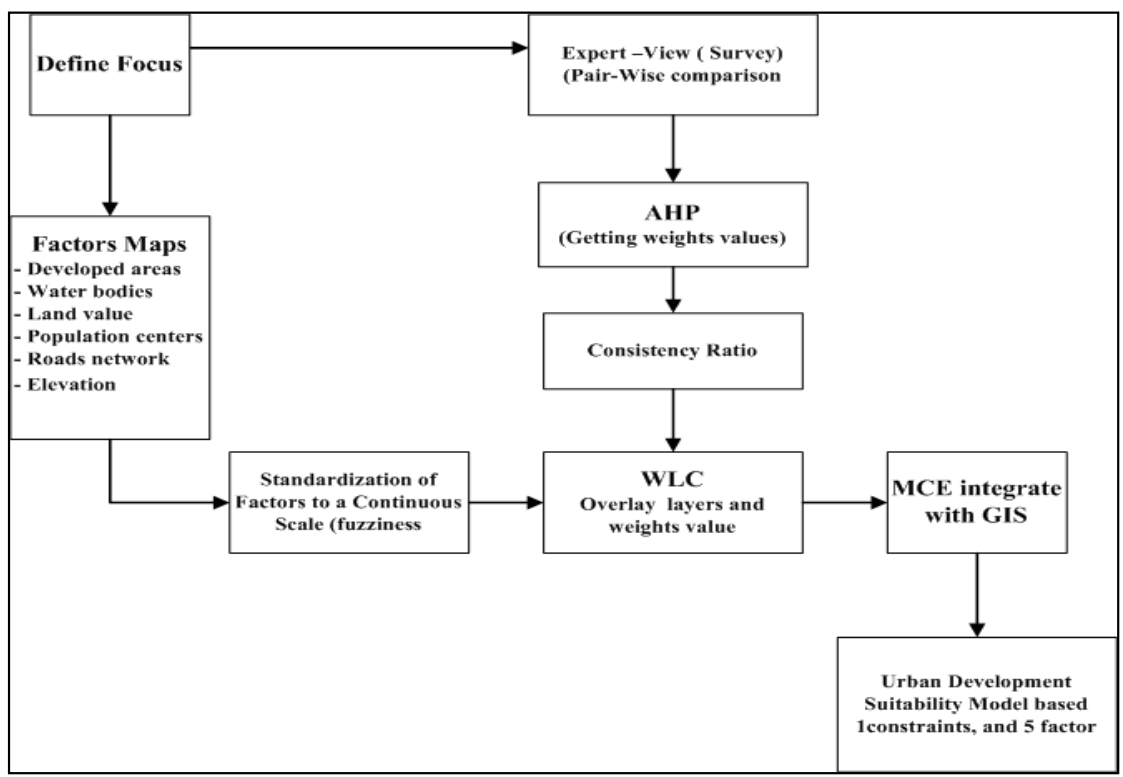

Figure 3: MCE- GIS applications to physical land suitability analysis 
MCE approach involves five steps namely define the objectives, identify the criteria, determine weights of the factors, map the criteria, and combine all the criteria and weights using MCE algorithm.

\section{IDENTIFYING THE CRITERIA AND WEIGHTS}

Based on the objective given above, criteria or factors influencing urban development were identified. The selection of factors for an MCE analysis was undertaken based on existing literature, defined by an analyst, or group of experts (López-Marrero and Yarnal, 2010). In this study, group of experts or stakeholders who have knowledge of the study area were interviewed. Criteria influencing urban development were divided into local and global factors and constraints. Although numerous factors influence urban growth and development such as accessibilities to public facilities, , land use types, socioeconomic conditions and demographic factors, management related factors, hydrological factors and soil related factors (Verburg and Chen, 2000; Chen et al., 2001; Shariff et al., 2010; Biotto et al., 2009) this study only used five factors namely proximity to water bodies, proximity to population centres, proximity to developed areas, existing from land value, and proximity to road networks. Based on these five criteria, their weights were determined using pair-wise comparison approach.Weight can be defined using the basic eigenvectors of a square reciprocal matrix of pairwise comparisons between the criteria (Malczewski, 2004). These comparisons were based on relative importance of two criteria used to determine the suitability of a defined objective. In this study, a pair of criteria were valued at the same time using the scale of nine points (degrees) ranging from $1 / 9$ to 9 as shown in Table 2 . The weights were derived based on the questionnaire, where urban planners and managers (experts) of related government departments in Penang state were interviewed. Based on the interviews undertaken, weights were derived for each criterion as shown in Table 3 below.

Table 2: Continuous Rating Scale Used For the Pair Wise Comparison of Factors in the Multi-Criteria Evaluation

\begin{tabular}{|c|c|c|c|c|c|c|c|c|}
\hline $1 / 9$ & $1 / 7$ & $1 / 5$ & $1 / 3$ & 1 & $\mathbf{3}$ & $\mathbf{5}$ & $\mathbf{7}$ & $\mathbf{9}$ \\
\hline extremely & Very & Strongly & Moderately & $\begin{array}{c}\text { Equally } \\
\text { important }\end{array}$ & Moderately & Strongly & Very & extremely \\
\hline \multicolumn{3}{|c|}{ Less important } & \multicolumn{5}{|c|}{ More important } \\
\hline
\end{tabular}

Source: Saaty (1977)

Table 3: Weights obtained for each criterion 


\begin{tabular}{|l|c|}
\hline Criteria & Weights \\
\hline Proximity to population centres & 0.28 \\
\hline Proximity to roads network & 0.40 \\
\hline Land value & 0.14 \\
\hline Proximity to developed areas & 0.04 \\
\hline Proximity to water bodies & 0.23 \\
\hline Consistency Ratio & $\mathbf{0 . 0 8}$ \\
\hline
\end{tabular}

Based on the weights obtained, weighted linear combination approach (WLC) was used to combine all criteria and obtain suitability map.

\section{RESULTS AND DISCUSSIONS}

\section{The Dynamic of Land Use Land Cover Changes in Balik Pulau from 1992 to 2010}

This study investigated urban expansion trends from 1992 and 2010 in Balik Pulau where statistics of urban expansion of urban area and speed of urban land change were measured. Penang had experienced rapid urbanization which has led to fundamental land use change during the last 40 years.

The land use conversion matrix in table 4 shows that the area underwent changes during the period 1992, 2002 and 2010.In 1992 agricultural lands was approximately 6171.32ha or $53.79 \%$ of the total land in the study area, but this area decreased to 4727.83 ha or $42.08 \%$, in 2002. Similarly, Tan et al. (2010) also found drastic decrease of agricultural land in Penang Island from 1999 to 2007 but built-up areas had increased from $31.23 \mathrm{~km}^{2}$ to $65.28 \mathrm{~km}^{2}$ or $109.03 \%$ over the 8-year period . In this study, the agricultural land decreased from 4727.83 ha in 2002 to 3883.0 ha in 2010Statistics obtained indicated that the change within 18 years was mainly reduction of agricultural lands, which decreased by the ratio $37 \%$ or 2288.0 ha. Also, urban uses increased by the ratio of $123.7 \%$ with 2193 ha (as shown in Tables 8 and 9).

Table 4: Agricultural lands and built-up areas in Balik Pulau 1992, 2002 and 2010.

\begin{tabular}{|c|c|c|c|c|c|c|c|c|}
\hline \multirow[t]{2}{*}{ Class } & \multicolumn{2}{|c|}{1992} & \multicolumn{2}{|c|}{2002} & \multicolumn{2}{|c|}{2010} & \multicolumn{2}{|c|}{$\begin{array}{c}\text { Total percentage } \\
\text { of changes among } \\
18 \text { years }\end{array}$} \\
\hline & ha & $\%$ & ha & $\%$ & ha & $\%$ & ha & $\%$ \\
\hline $\begin{array}{l}\text { Agricultural } \\
\text { lands }\end{array}$ & 6171.3 & 53.8 & 4727.83 & 42.1 & 3883 & 35.8 & -2288 & 37.0 \\
\hline Built-up areas & 1793.2 & 15.6 & 3235.4 & 28.2 & 3987.8 & 34.9 & +2193 & 123.7 \\
\hline
\end{tabular}


In contrast, built-up areas had increased significantly from 1793.2 ha in 1992, which constituted $15.6 \%$ of the total of study area to approximately 3235.4 ha in 2002 ; so the proportion of urban uses had increased by the ratio of $28.2 \%$ (as shown in Table 4), an increase of 1442.2 ha during this 10 years with an annual rate of 144.21 ha (Figure 4). This is equal to the rate of annual loss of agricultural lands. It could be concluded that $98 \%$ of urban expansion in the study area occurred at the expense of agricultural lands.

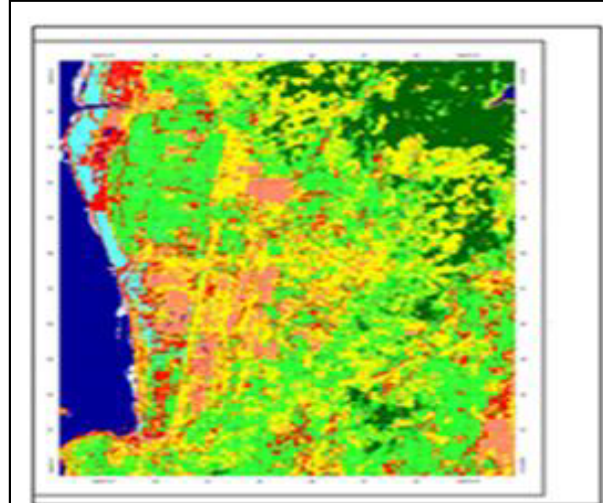

B) 2002

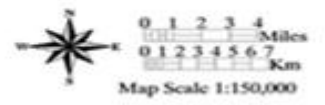

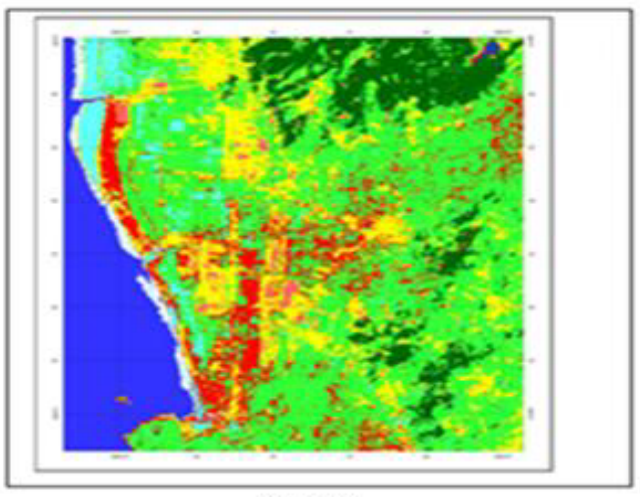

(A) 1992

Legend

Agric ultumal lands forest

Mixed agricultural lands

Built-up areas

Barren land

Sand

Mangrove

Water

Figure 4: Land Cover Classification of Balik Pulau 1992 and 2002 


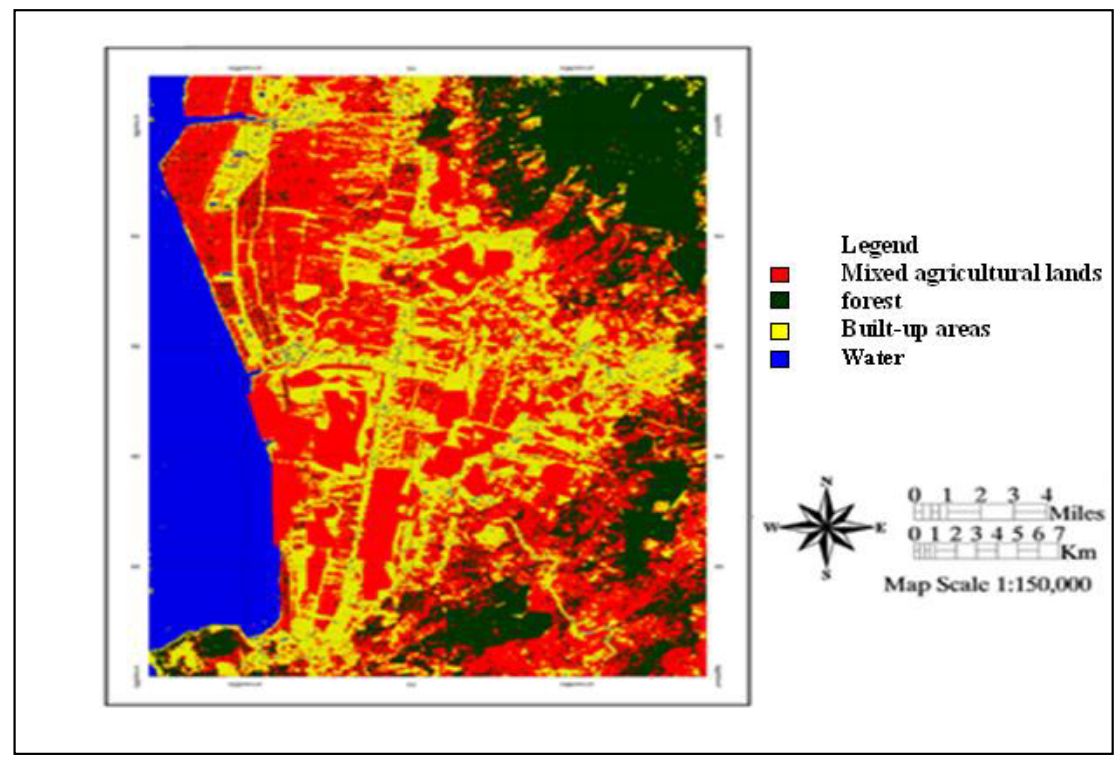

Figure 5: Land Cover Classification of Balik Pulau-2010

\section{Identifying Potential Sites for Urban Development}

The findings in the previous section indicated that the study area has experienced drastic increase on built-up areas at the expense of agriculture land. Although agriculture activities may contribute small portion (less than $10 \%$ ) of state's GDP, this area should be maintenance and conserved. This study then, identified potential areas for future development such that planners and decision makers may anticipate areas likely gong to experience development pressure. Based on factors and weights calculated, five factors and constraint used were mapped (see Figure 6). Then, weighted linear combination approach was used to combine all criteria and constraint. The result obtained is shown in Figure 7 below. 


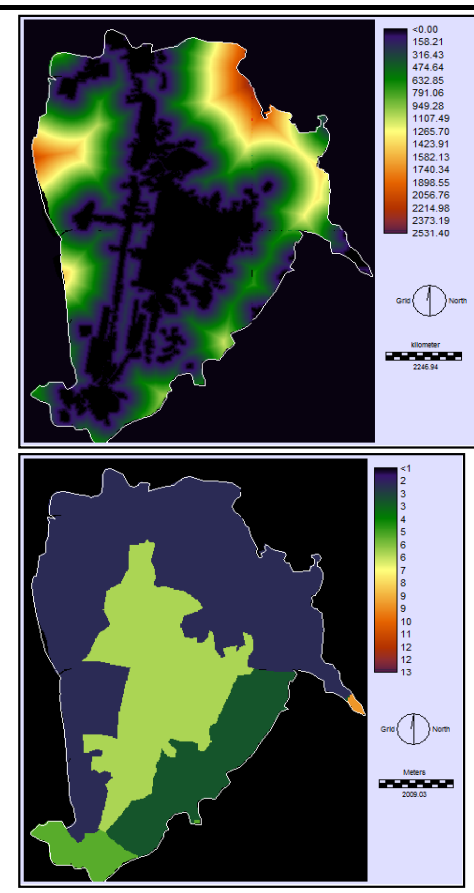

(a) Proximity to Developed Areas

(b) Proximity to Water Bodies

(c) Land Value
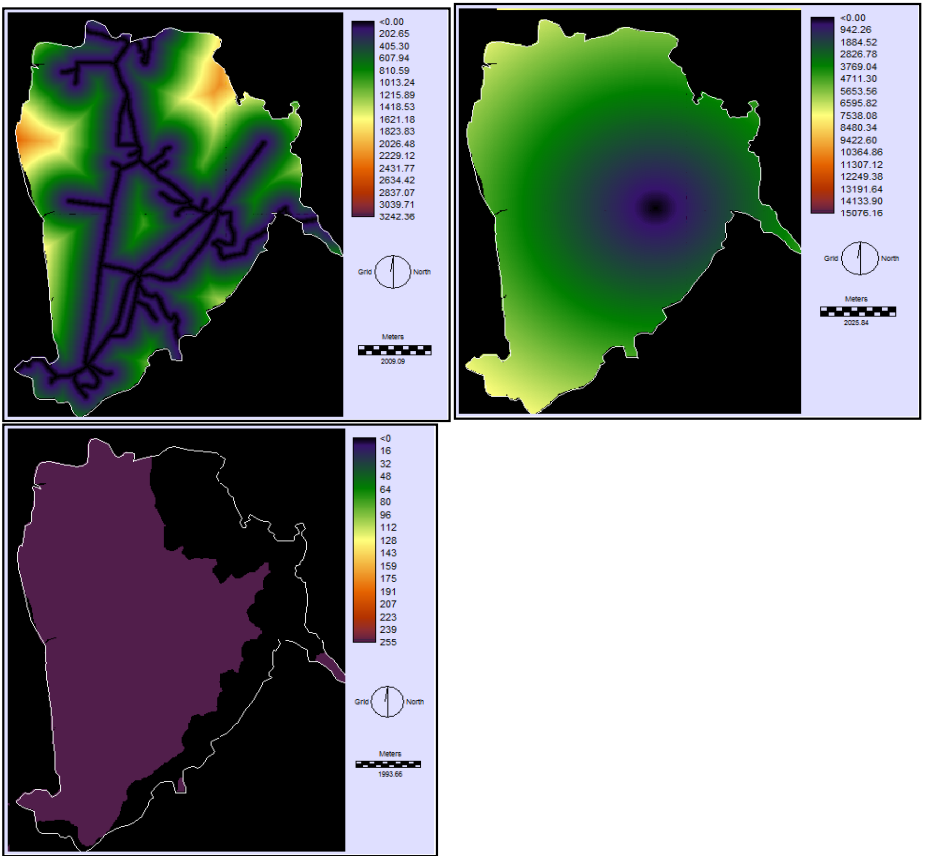

(d) Proximity to Population Center

(e) Proximity to Roads Network

Elevation

Figure 6: Criteria used in determining suitability map 
Based on GIS-MCE analysis this study identified potential sites for future development in Balik Pulau. The analysis produced a map of several classes: low, moderate, or high suitability for urban development. The final suitability map constructed by a linear combination approach represented areas characterized by different potentials for urban development assigned that values between 1 and 5. A color-coded example of the resulted map is shown in Figure 8. Based on the analysis areas located nearby hills with low elevation ranged from 5 to 20 degree and a little bit far from far agricultural land is considered as a most suitable sites for future urban development. Most of the low lands (flat area) were considered as unsuitable areas for urban development to preserve agricultural lands. The resulted suitability map provided clear information for urban planners and managers to identify new urban sites in Balik Pulau. By so doing planners ensure that this new sites have less negative impact on rural community and agricultural lands. The 'highest suitable' category on the other hand, signifies areas with high extent of urbanization, in other words, they are low sensitive areas. Activities to be allowed for urban activities included industrial, commercial, housing and tourism. The study found that moderately suitable sites were actually located around existing Balik Pulau. Less suitable sites category is assigned to the areas that depict the less suitable urban development. This area will therefore be less likely to be developed for future urban development.

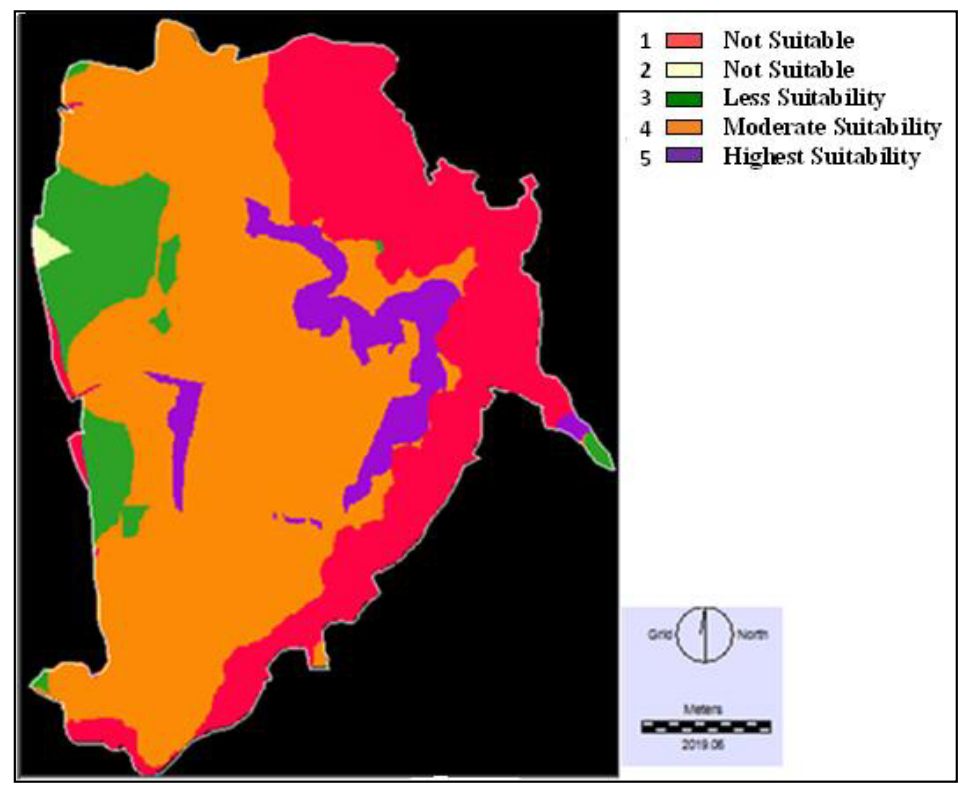

Figure 7: Final Suitability Map of Future Development Sites in Balik Pulau 
The result of the suitability analysis provided important information to determine potential areas for development which preserved agricultural lands in study area. In addition, urban development sites shall not be placed near agricultural lands to avoid the negative effects of urban phenomenon on the farmers and crops.

The study provides simple land use land cover changes to investigate the impact of built-up areas expansion on agricultural land. Furthermore, GIS-MCE analysis was undertaken to show potential areas for development is quite small and urgently require close monitoring and planning. It should be noted that this study was undertaken to visualize affect areas based on five criteria and one constraint. Further analysis may be undertaken to predict the dynamic of land use land cover changes using urban spatio-temporal model.

\section{CONCLUSION}

Generally, Balik Pulau has experienced significant changes in size, speed and patterns of urban expansion. This expansion is at the expanse of agricultural lands which experienced significant reduction since 1992 to 2010. Furthermore, based on the GIS-MCE analysis, the paper comes out urbanization is expanded very rapidly in Balik Pulau and several potential sites are underway to be developed in the near future. Therefore, it is important to continuously investigated and monitored urban expansion in Balik Pulau. Furthermore, it would be useful to identify areas likely to experience development pressure, in order to help planners in planning these suburban areas. Having both visual and quantity result led the integration of GIS-MCE to be a very useful and powerful technique in guiding urban planners and decision for implementing sustainable urban land use. Moreover the tool has its ability to include the ideas of public communities thus both methods bottom up and top down approaches are implemented in planning. In addition the technique is very simple and flexible and can be fit in various applications related to urban issues. Despite this still the application of this technique is urbanization is very rare particularly in the third countries.

\section{ACKNOWLEDGMENT}

We would like to thank Ministry of Education Malaysia for partially fund the project through Fundamental Research Grant Scheme 203/PHUMANITI/6711472, Geography Section, School of Humanities, University Sains Malaysia, and Penang GIS office, Town and Country Planning Department, Penang State for their support as the main sources of our research data. 


\section{REFERENCES}

Abdul Rahman, S, B. (2000), population and housing census of Malaysia ,population distribution by local author areas and mukims,pp1-367.

Agus, M. R., Doling, J., \& Lee, D. S. (2002). Housing policy systems in south and east Asia: Palgrave Macmillan New York.

Biotto, G., Silvestri, S., Gobbo, L., Furlan, E., Valenti, S., \& Rosselli, R. (2009). GIS, multi-criteria and multi-factor spatial analysis for the probability assessment of the existence of illegal landfills. International Journal of Geographical Information Science, 23(10), 1233-1244.

Bukhari, Zubaidah (2010) Integration of Geographical Information System and Multi Criteria Evaluation for Identification of Suitable Urban School Sites. Masters thesis, Universiti Putra Malaysia.

Carver, S. (1996). Wilderness Britain: Using GIS and multi-criteria evaluation techniques to map the wilderness continuum: School of Geography, University of Leeds.

Chadchan, J., Shankar, R. (2012) An analysis of urban growth trends in the post-economic reforms period in India, International Journal of Sustainable Built Environment, 1, $36-49$.

Chan, N. W. (2010). Impacts of human habitat development on the environment-challenges and the way forward. Malaysian Journal of Environmental Management, 11(2), 3-20.

Chen, K., Blong, R., \& Jacobson, C. (2001). MCE-RISK: integrating multicriteria evaluation and GIS for risk decision-making in natural hazards. Environmental Modelling \& Software, 16(4), 387-397.

Chen, J. (2014). GIS-based multi-criteria analysis for land use suitability assessment in City of Regina. Environmental Systems Research 2014, 3:13.

Chuvieco, E. (1993). Integration of linear programming and GIS for land-use modelling. International Journal of Geographical Information Science, 7(1), 71-83.

Cromley, R. G., \& Huffman, F. T. (2006). Modeling situation factors used in MCE procedures for raster GIS. Transactions in GIS, 10(2), 239-251.

Drobne, S., \& Lisec, A. (2009). Multi-attribute decision analysis in GIS: weighted linear combination and ordered weighted averaging. Informatica: An International Journal of Computing and Informatics, 33(4), 459-474. 
Elhadary, Y., \& Saman, N. (2015) Integrating Geographic Information System and Discriminant Analysis in Modelling Urban Spatial Growth: An Example from Seberang Perai Region, Penang State, Malaysia. Asian Social Science; Vol. 11, No. 2; 2015 .

Elhadary, Y., Narimah S \& Franklin Obeng-Odoom (2013) Development at the Peri-Urban Area and Its Impact on Agricultural Activities: An Example from the Seberang Perai Region, Penang State, Malaysia, Agroecology and Sustainable Food Systems, 37:7, 834-856

Fischer, M. M., \& Nijkamp, P. (1993). Geographic information systems, spatial modelling and policy evaluation, in Geographic information systems, spatial modelling and policy evaluation. $\left(1^{\text {st }}\right.$ ed.).

Fekade, W. (2000). Deficits of formal urban land management and informal responses under rapid urban growth, an international perspective. Habitat International, 24(2), 127150 .

Hepinstall, J. A., Alberti, M., \& Marzluff, J. M. (2008). Predicting land cover change and avian community responses in rapidly urbanizing environments. Landscape ecology, 23(10), 1257-1276.

Jankowski, P. (1995). Integrating geographical information systems and multiple criteria decision-making methods. International Journal of Geographical Information Systems, 9(3), 251-273.

Jat, M. K., Garg, P., \& Khare, D. (2008). Monitoring and modelling of urban sprawl using remote sensing and GIS techniques. International Journal of Applied Earth Observation and Geoinformation, 10(1), 26-43.

Jiang, H., \& Eastman, J. R. (2000). Application of fuzzy measures in multi-criteria evaluation in GIS. International Journal of Geographical Information Science, 14(2), 173-184.

Lambin, E. F., Geist, H. J., \& Lepers, E. (2003). Dynamics of land-use and land-cover change in tropical regions. Annual review of environment and resources, 28(1), 205-241.

LaGro, J. A., \& DeGloria, S. D. (1992). Land use dynamics within an urbanizing nonmetropolitan county in New York State (USA). Landscape ecology, 7(4), 275-289.

López-Marrero, T., \& Yarnal, B. (2010). Putting adaptive capacity into the context of people's lives: a case study of two flood-prone communities in Puerto Rico. Natural Hazards, 52(2), 277-297. 
Ma, Y., \& Xu, R. (2010). Remote sensing monitoring and driving force analysis of urban expansion in Guangzhou City, China. Habitat International, 34(2), 228-235.

Malczewski, J. (2004). GIS-based land-use suitability analysis: a critical overview. Progress in Planning, 62(1), 3-65.

Malczewski, J. (2002). Fuzzy screening for land suitability analysis. Geographical and Environmental Modelling, 6(1), 27-39.

Malczewski, J. (1999). GIS and multicriteria decision analysis, Canada, John Wiley\&Sons.

Malczewski, J. (1996). A GIS-based approach to multiple criteria group decision-making. International Journal of Geographical Information Systems, 10(8), 955-971.

Moeinaddini, M., Khorasani, N., Danehkar, A., \& Darvishsefat, A. A. (2010). Siting MSW landfill using weighted linear combination and analytical hierarchy process (AHP) methodology in GIS environment (case study: Karaj). Waste Management, 30(5), 912-920.

Openshaw, S. (1996). Developing GIS-relevant zone-based spatial analysis methods. Spatial analysis: modelling in a GIS environment, 55-73.

Pourebrahim, S., Hadipour, M., \& Bin Mokhtar, M. (2011). Integration of spatial suitability analysis for land use planning in coastal areas; case of Kuala Langat District, Selangor, Malaysia. Landscape and Urban Planning, 101(1), 84-97.

Raddad, S., Salleh, A., Samat, N . (2010). Determinants of agricultural land use change in Palestinian urban environment :Urban planners at local governments perspective, American - Eurasian Journal of sustainable agricultural, 4, 30-38.

Rainis R, Ismail W, Shariff N. Estimating sediment yield of a small catchment in a tropical region using the AGNPS model: the Waterfall River catchment, Penang, Malaysia. Journal of Environmental Hydrology. 2002;10:1-10.

Reshmidevi, T., Eldho, T., \& Jana, R. (2009). A GIS-integrated fuzzy rule-based inference system for land suitability evaluation in agricultural watersheds. Agricultural Systems, 101(1-2), 101-109.

Saaty, T. L. (1987). Rank generation, preservation, and reversal in the analytic hierarchy decision process. Decision sciences, 18(2), 157-177.

Saaty, T. L. (1977). A scaling method for priorities in hierarchical structures. Journal of mathematical psychology, 15(3), 234-281. 
Samat, N. (2010). Assessing land use land cover changes in Langkawi island: towards sustainable urban living. Malaysian Journal of Environmental Management, 11(1), 48-57.

Samat, N. (2006). Characterizing the scale sensitivity of the cellular automata simulated urban growth: A case study of the seberang perai region, Penang State, Malaysia. Computers, Environment and Urban Systems, 30(6), 905-920.

Samat, N. (2002). A geographic information system and cellular automata spatial model of urban development for Penang State, Malaysia. Phd.Thesis. University of Leeds.

Sabbar, K. Elhadary, Y. and Samat, N. (2015) GIS and Remote Sensing Techniques for measuring agriculture land loss in Balik Pulau Region of Penang State, Malaysia. Journal of Agriculture and Rural Development, 5(2)2015: 30-41

Shariff, N., Gairola, S., \& Talib, A. (2010). Modelling urban land use change using Geographically Weighted Regression and the implications for sustainable environmental planning.

Umrikar, B. (2013) Multi Criteria approach for analysis of Land Suitability for Urban Expansion. The Journal of Geography and Geology. Photon 117 (2013) 170-176.

Verburg, P. H., \& Chen, Y. Q. (2000). Multiscale characterization of land-use patterns in China. Ecosystems, 3(4), 369-385.

Voogd, H. (1983). Multicriteria evaluation for urban and regional planning: Pion London.

Weerakoon, K. (2014). Suitability Analysis for Urban Agriculture Using GIS and MultiCriteria Evaluation. International Journal of Agricultural Science and Technology (IJAST) Volume 2 Issue 2, May 2014

$\mathrm{Xu}, \mathrm{H}$., Wang, X., \& Xiao, G. (2000). A remote sensing and GIS integrated study on urbanization with its impact on arable lands: Fuqing City, Fujian Province, China. Land Degradation \& Development, 11(4), 301-314. 